\title{
Chemotherapy for testicular cancer induces acute alterations in diastolic heart function
}

\author{
L D van Schinkel ${ }^{1}$, P M Willemse ${ }^{2}$, R W van der Meer ${ }^{3}$, J Burggraaf ${ }^{4}, S$ G C van Elderen ${ }^{3}$, J W A Smit ${ }^{1}$,
} A de Roos ${ }^{3}$, S Osanto ${ }^{2}$ and $\mathrm{H} \mathrm{J} \mathrm{Lamb}{ }^{3}$

${ }^{1}$ Department of Endocrinology, Albinusdreef 2, 2333 ZA Leiden, The Netherlands; ${ }^{2}$ Department of Clinical Oncology, Albinusdreef 2, 2333 ZA Leiden, The Netherlands; ${ }^{3}$ Department of Radiology Leiden University Medical Center, Albinusdreef 2, 2333 ZA Leiden, The Netherlands and ${ }^{4}$ Centre for Human Drug Research, Zernikedreef 10, 2333 CL Leiden, The Netherlands

Background: After treatment with cisplatin-based chemotherapy for testicular cancer (TC), patients have higher prevalence of cardiovascular complications after long-term follow up. Little is known about acute cardiovascular effects of cisplatin-based chemotherapy. The aim of this study was to explore acute effects of chemotherapy on cardiac function in patients treated for TC.

Methods: Fourteen TC patients (age 34.6 \pm 12.3 years) were studied before and 3 months after start with cisplatin-based chemotherapy. Cardiac function was assessed with magnetic resonance imaging. Fasting glucose and insulin levels were measured and insulin sensitivity, reflected by the quantitative insulin sensitivity index (Quicki index), was calculated.

Results: Left ventricular (LV) end-diastolic volume and LV stroke volume (SV) significantly decreased from $192 \pm 27$ to $175 \pm 26 \mathrm{ml}$ $(P<0.05)$ and $109 \pm 18$ to $95 \pm 16 \mathrm{ml}(P<0.05)$, respectively. The ratio of early and atrial filling velocities across the mitral valve, a parameter of diastolic heart function, decreased after chemotherapy from $1.87 \pm 0.43$ to $1.64 \pm 0.45(P<0.01)$. Metabolic parameters were unfavourably changed, reflected by a decreased Quicki index, which reduced from $0.39 \pm 0.05$ to $0.36 \pm 0.05$ $(P<0.05)$.

Conclusion: Chemotherapy for TC induces acute alterations in diastolic heart function, paralleled by unfavourable metabolic changes. Therefore, early after chemotherapy, metabolic treatment may be indicated to possibly reduce long-term cardiovascular complications.

Testicular cancer (TC) is the most frequent form of cancer in young men. The prognosis of TC is good, with high cure rates since the introduction of treatment with cisplatin-based chemotherapy (International Germ Cell Consensus Classification, 1997; Einhorn, 1997). Because of the increasing number of survivors with a long life expectancy, understanding and prevention of short-term and long-term cardiovascular effects of chemotoxicity is very important.

Treatment of TC with cisplatin, bleomycin and etoposide (BEP) combination chemotherapy is associated with acute vascular toxicity and subacute changes in cardiac function (Stefenelli $e t$ al, 1988; Altena et al, 2009), as well as with long-term cardiovascular disease (Bajraktari et al, 2006; Battiprolu et al, 2010). Previous studies showed that cisplatin and bleomycin induce alterations in endothelial function and endothelial damage in vitro (Montiel et al, 2009; Nuver et al, 2010). These findings suggest direct toxic effects of chemotherapy on the cardiovascular system. Little is known about acute effects of cisplatin-based chemotherapy on cardiac function. More insight in the pathophysiology of the direct toxic effects of cisplatin-based chemotherapy on the cardiac function and vessel wall is relevant to possibly prevent long-term cardiovascular disease. One previous study reported subacute deterioration of diastolic function, assessed with echocardiography 10 months after cisplatin-based chemotherapy (Altena et al, 2009).

Indirect effects of chemotherapy also seem to have a role in the increased risk of cardiovascular complications. For example, early 
after treatment with cisplatin-based chemotherapy changes in serum lipids have been described (Raghavan et al, 1992). In addition, higher incidences of hypercholesterolaemia, hypertension, microalbuminuria, obesity, elevated insulin-glucose ratio and thereby metabolic syndrome have been reported at least 3 years after chemotherapy (Battiprolu et al, 2010; Dinh et al, 2010; Devaraj et al, 2011). The acute effects of chemotherapy, defined as effects occurring 3 months after start of chemotherapy, on these risk factors are largely unknown. The aforementioned indirect risk factors are all independently associated with a higher risk of cardiovascular disease and may contribute to the overall increased risk of cardiovascular complications after treatment with cisplatinbased chemotherapy. The increased risk of cardiovascular disease in cured TC patients after cisplatin-based chemotherapy is probably a combination of direct and indirect effects of chemotherapy (Einhorn, 1997; Devaraj et al, 2011). Early changes in cardiac function and risk factors may have prognostic value for long-term development of cardiovascular complications (Altena et al, 2011). Magnetic resonance (MR) imaging is a highly reproducible imaging modality to assess cardiac function. Furthermore, myocardial triglyceride (TG) content can be measured with proton $\left({ }^{1} \mathrm{H}\right) \mathrm{MR}$ spectroscopy (van der Meer et al, 2007). In addition, abdominal visceral and subcutaneous fat volume can be accurately assessed with MRI (Rijzewijk et al, 2008). Therefore, the purpose of this study was to investigate acute changes in cardiac function and myocardial TG, in relation to body fat distribution and metabolic parameters 3 months after start with chemotherapy for TC, assessed with MR-techniques.

\section{MATERIALS AND METHODS}

This study was approved by the local medical ethics committee, and all subjects gave written informed consent. Metastatic TC patients, scheduled for first-line curative cisplatin-based combination chemotherapy in the Leiden University Medical Center were included between 2007 and 2009. Exclusion criteria were comorbidities, including cardiovascular disease and diabetes mellitus.

Patients received three or four cycles of standard BEPchemotherapy repeated every 3 weeks. Each cycle consisted of intravenously administered etoposide $\left(100 \mathrm{mg} \mathrm{m}^{-2}\right.$ over $1 \mathrm{~h}$, days $1-5)$, cisplatin $\left(20 \mathrm{mg} \mathrm{m}^{-2}\right.$ over $4 \mathrm{~h}$, days $\left.1-5\right)$ and bleomycin (30 IUSP over $30 \mathrm{~min}$ ) at days 2,8 and 15 . According to Dutch oncological guidelines, TC patients with good prognosis were treated with three cycles of BEP and patients with intermediate prognosis were treated with four cycles BEP. One patient, in addition received paclitaxel $\left(175 \mathrm{mg} \mathrm{m}^{-2}\right)$ on day 1 of each of his four chemotherapy cycles as part of a randomized phase III study comparing paclitaxel BEP and standard BEP in patients with intermediate prognosis TC. All patients were orchidectomised before adjuvant chemotherapeutic treatment.

Body mass index was determined at baseline and after chemotherapy. Fasting serum glucose, insulin, total cholesterol, high-density lipoprotein (HDL), low-density lipoprotein (LDL) and TGs were determined. Insulin resistance was assessed with the quantitative insulin sensitivity index (Quicki index), which is calculated using the formula: $1 /(\log$ (fasting insulin $\left.\mu \mathrm{Uml}^{-1}\right)+\log \left(\right.$ fasting glucose $\left.\mathrm{mgdl}^{-1}\right)$ ) (Katz et al, 2000). Renal function defined as estimated glomerular filtration rate was calculated with the Modification of Diet in Renal Disease (MDRD) equation: $186 \times\left(\right.$ serum creatinine $\mu \mathrm{moll}^{-1} /$ $88.4)^{-1.154} \times(\text { age })^{-0.203}$.

Patients underwent MRI before start and shortly after the last chemotherapy cycle, which was approximately 3 months after start of chemotherapy.
Blood pressure and heart rate were measured during MRI using a semiautomated sphygmomanometer (Dinamap, Critikon, Tampa, FL, USA).

We have included part of a study group from a previous study, describing metabolic changes and MRI assessment of hepatic TG content, aortic pulse wave velocity and abdominal fat mass in TC patients undergoing curative chemotherapy at 3 and 9 months after start of chemotherapy (submitted).

\section{Magnetic resonance imaging protocol}

Left and right ventricular function. Cardiac imaging was performed using a 1.5 Tesla whole-body MRI scanner (Gyroscan ACS-NT15; Philips Medical Systems, Best, The Netherlands) after a night fast. The heart was imaged in short-axis orientation, using electrocardiographically gated breath-hold cine steady-state free-precession sequences as previously described (Lamb et al, 1996). Imaging parameters were: repetition time (TR) $3.4 \mathrm{~ms}$, echo time (TE) $1.7 \mathrm{~ms}$, flip angle (FA) $35^{\circ}$, field of view (FOV) $400 \times 320 \mathrm{~mm}$, slice thickness $10 \mathrm{~mm}$, no slice gap was used. To assess LV and RV systolic function, endocardial contours were manually drawn, using MASS software (Medis, Leiden, The Netherlands). Left ventricular and RV ejection fraction (EF), $\mathrm{SV}$, end-diastolic volume (EDV) and end-systolic volume were assessed. Epicardial contours of the LV were drawn to calculate LV end-diastolic mass.

To assess LV and RV diastolic function, the flow across mitral and tricuspid valve was measured using an electrocardiographically gated gradient echo sequence with velocity-encoding. Scan parameters were: $\mathrm{TR}=9.1 \mathrm{~ms}, \mathrm{TE}=1.0 \mathrm{~ms}, \mathrm{FA}=20^{\circ}$, slice thickness $=8 \mathrm{~mm}, \quad F O V=350 \mathrm{~mm}^{2}$ and matrix $=256 \times 256$ pixels. Flow velocities in early diastole (E) and at atrial contraction (A) were measured and peak flow ratio was calculated (E/A ratio) using FLOW software (Medis). The downslope of the early filling phase (E deceleration peak) and LV filling pressures $(\mathrm{E} / \mathrm{Ea})$ were calculated (Pattynama et al, 1993; Paelinck et al, 2005)

Myocardial TG content. Myocardial ${ }^{1} \mathrm{H}-\mathrm{MR}$ spectra were obtained as described before (van der Meer et al, 2007). A voxel was positioned in the myocardial interventricular septum in endsystole. ECG triggering and respiratory pencil beam navigator were used during acquisition. Spectra with water suppression were acquired with $\mathrm{TE}=26 \mathrm{~ms}$ and $\mathrm{TR} \geqslant 3000 \mathrm{~ms}$. A total of 1024 data points were collected using a $1000 \mathrm{~Hz}$ spectral width and averaged over 128 acquisitions. Spectra without water suppression with $\mathrm{TR}=10 \mathrm{~s}$ and four averages were obtained without changing other parameters. Spectroscopic data were fitted using validated software (jMRUI version 2.2, Leuven, Belgium; Naressi et al, 2001). Myocardial TG content was calculated as (amplitude of TG signal/amplitude water signal) $\times 100 \%$.

Pericardial fat. Pericardial fat was quantified as described previously using electrocardiographically gated breath-holds with balanced turbo-field echo MR sequence (Jonker et al, 2010). Imaging parameters were: $\mathrm{TR}=3.2 \mathrm{~ms}, \mathrm{TE}=1.60 \mathrm{~ms}, \mathrm{FA}=50^{\circ}$, slice thickness $=10 \mathrm{~mm}$ and $\mathrm{FOV}=400 \mathrm{~mm}^{2}$. The four-chamber view was analysed, with the plane of respiratory mitral and tricuspid valves as margins. To quantify periventricular fat volume, contours around pericardial fat were drawn manually at endsystole and multiplied by the thickness of the slice. We used MASS for postprocessing.

Visceral and subcutaneous fat. Visceral and subcutaneous fat volumes were imaged using a turbo spin echo imaging sequence (Rijzewijk et al, 2008). During one breath-hold, three consecutive transversal slices of $10 \mathrm{~mm}$ thickness were scanned at the fifth 
lumbar vertebrae. Imaging parameters were: $\mathrm{TR}=168 \mathrm{~ms}, \mathrm{TE}=11$ $\mathrm{ms}$ and $\mathrm{FA}=90^{\circ}$. Contours were drawn around visceral and subcutaneous abdominal fat depots using MASS. Visceral and subcutaneous fat areas of each slice were multiplied by the slice thickness to acquire a volume, the volumes of all three slices were summed.

Statistical analysis. Statistical analyses were performed using SPSS 17.0 (SPSS Inc., Chicago, IL, USA). We used two-tailed paired $t$-tests to compare the two study time points, as all data were normally distributed. To determine which significantly changed parameters influenced the differences of the other cardiac parameters, univariate regression analyses were performed. In these regression analyses, the delta of the significantly changed parameter (the difference of the parameter before and after chemotherapy) was the independent variable and the delta of the cardiac parameter of interest was the dependent variable. In case of a significant influence, the corrected difference between baseline and follow-up was extracted from the regression analysis. A $P$-value of $<0.05$ was considered statistically significant. Data are expressed as mean \pm s.d.

\section{RESULTS}

Forty consecutive patients were asked to participate. Twenty-one patients could not participate, based on logistic reasons $(N=5)$, refusal or non-eligibility $(N=16)$. These patients had unwillingness to undergo frequent blood drawings during chemotherapy or MRI. Nineteen patients underwent baseline MRI. Five patients missed the follow-up MRI due to treatment-related sickness $(N=2)$, study withdrawal $(N=2)$ and treatment-related death $(N=1)$. Accordingly, 14 patients were included in data analysis of the present study. Three HDL concentration and one insulin concentration were missing.

Table 1 shows the tumour characteristics and staging. Table 2 shows the patient characteristics at baseline and after chemotherapy. Average age was $34.6 \pm 12.3$ years. Average time between the two MRI scans was $2.6 \pm 0.5$ months. Time between the last day of chemotherapy and the MRI after chemotherapy was $18 \pm 18$ days. Weight, BMI and blood pressure did not change during follow-up. Heart rate increased significantly from $64 \pm 9$ to $76 \pm 15$ b.p.m. $(P=0.007)$. Laboratory parameters at baseline and at follow-up are described in Table 2. The Quicki index decreased, from $0.39 \pm 0.05$ to $0.36 \pm 0.05 \quad(P=0.018)$, reflecting greater insulin resistance.

Left and right ventricular function. Owing to technical difficulties, two diastolic LV and RV scans and one systolic RV were missing. Left ventricular EDV and SV significantly decreased, respectively, from $192 \pm 27$ to $175 \pm 26 \mathrm{ml}(P=0.012)$ and from $109 \pm 18$ to $95 \pm 16 \mathrm{ml}(P=0.025)$ (Table 3$)$. Although LV EDV and SV were significantly influenced by the increased heart rate, the difference between baseline and follow-up remained significant

Table 1. Tumour and staging characteristics of the patients

\begin{tabular}{|l|l|}
\hline Histology; $\boldsymbol{n}(\%)$ \\
\hline Seminoma & $4(28.6)$ \\
Non-seminoma & $2(14.3)$ \\
Combined tumour & $8(57.1)$ \\
\hline TNM tumour staging; $\boldsymbol{n}(\%)$ & $7(50)$ \\
\hline Stage II (para-aortic lymph node metastasis) & $7(50)$ \\
Stage III (distant metastasis)
\end{tabular}

Table 2. Patient characteristics at baseline and after chemotherapy

\begin{tabular}{|c|c|c|}
\hline & Baseline & After chemotherapy \\
\hline Systolic blood pressure $(\mathrm{mmHg})$ & $123 \pm 17$ & $118 \pm 11$ \\
\hline Diastolic blood pressure $(\mathrm{mmHg})$ & $73 \pm 11$ & $70 \pm 12$ \\
\hline Heart rate (b.p.m.) & $64 \pm 9$ & $76 \pm 15^{\dagger}$ \\
\hline Weight (kg) & $83.3 \pm 15.5$ & $84.5 \pm 18.5$ \\
\hline Body mass index $\left(\mathrm{kg} \mathrm{m}^{-2}\right)$ & $24.4 \pm 4.0$ & $24.7 \pm 4.6$ \\
\hline Cholesterol $\left(\mathrm{mmoll}^{-1}\right)$ & $4.7 \pm 1.3$ & $5.5 \pm 1.5^{\dagger}$ \\
\hline Estimated GFR (MDRD), $\mathrm{ml} \mathrm{min}^{-1}$ & $102 \pm 16$ & $113 \pm 18^{\dagger}$ \\
\hline $\mathrm{HDL}\left(\mathrm{mmoll}^{-1}\right)$ & $1.30 \pm 0.31$ & $1.36 \pm 0.25$ \\
\hline $\mathrm{LDL}\left(\mathrm{mmol} \mathrm{I}^{-1}\right)$ & $3.12 \pm 1.15$ & $3.74 \pm 1.41^{*}$ \\
\hline Triglycerides $\left(\mathrm{mmoll}^{-1}\right)$ & $1.16 \pm 0.60$ & $1.64 \pm 1.11$ \\
\hline Fasting glucose $\left(\mathrm{mmoll}^{-1}\right)$ & $5.1 \pm 0.5$ & $5.2 \pm 0.6$ \\
\hline Insulin $\left(\mathrm{mUI}^{-1}\right)$ & $6.2 \pm 5.0$ & $9.8 \pm 6.8$ \\
\hline Quicki index & $0.39 \pm 0.05$ & $0.36 \pm 0.05^{*}$ \\
\hline \multicolumn{3}{|c|}{$\begin{array}{l}\text { Abbreviations: } \quad H D L=\text { high-density lipoprotein; } \quad L D L=\text { low-density lipoprotein } \\
M D R D=\text { Modification of Diet in Renal Disease; Quicki index = quantitative insulin sensitivity } \\
\text { index. }{ }^{*} P<0.05 .{ }^{\dagger} P<0.01 \text {. Data are mean } \pm \text { s.d. }\end{array}$} \\
\hline
\end{tabular}

Table 3. Parameters of myocardial function, assessed with MRI at baseline and after chemotherapy

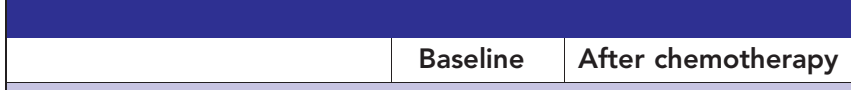

Left ventricle

\section{Systolic function}

\begin{tabular}{|l|c|c|}
\hline EDV $(\mathrm{ml})$ & $192 \pm 27$ & $175 \pm 26^{*}$ \\
ESV $(\mathrm{ml})$ & $84 \pm 16$ & $80 \pm 14$ \\
$\mathrm{SV}(\mathrm{ml})$ & $109 \pm 18$ & $95 \pm 16^{*}$ \\
$\mathrm{CO}\left(\mathrm{ml} \mathrm{min}{ }^{-1}\right)$ & $6816 \pm 1112$ & $7050 \pm 1160$ \\
EF $(\%)$ & $56.6 \pm 5.3$ & $54.3 \pm 5.1$ \\
\hline
\end{tabular}

\section{Diastolic function}

\begin{tabular}{l|c|c}
\hline E peak filling rate $\left(\mathrm{ml} \mathrm{s}^{-1}\right)$ & $657 \pm 119$ & $662 \pm 122$ \\
E deceleration $\left(\mathrm{ml} \mathrm{s}^{-2} \times 10^{-3}\right)$ & $6.3 \pm 2.2$ & $6.0 \pm 1.7$ \\
A-peak filling rate $\left(\mathrm{ml} \mathrm{s}^{-1}\right)$ & $362 \pm 78$ & $425 \pm 111^{*}$ \\
E/A-peak ratio & $1.87 \pm 0.43$ & $1.64 \pm 0.45^{\dagger}$ \\
E/Ea & $6.8 \pm 2.0$ & $6.8 \pm 2.0$ \\
\hline
\end{tabular}

Right ventricle

Systolic function

\begin{tabular}{|l|c|c}
\hline EDV $(\mathrm{ml})$ & $210 \pm 32$ & $196 \pm 38^{*}$ \\
ESV $(\mathrm{ml})$ & $105 \pm 29$ & $103 \pm 25$ \\
SV $(\mathrm{ml})$ & $105 \pm 14$ & $93 \pm 16^{*}$ \\
CO $\left(\mathrm{ml} \mathrm{min}{ }^{-1}\right)$ & $6595 \pm 927$ & $6976 \pm 851$ \\
EF $(\%)$ & $49.9 \pm 6.7$ & $47.9 \pm 4.6$
\end{tabular}

Diastolic function

\begin{tabular}{|l|c|c|}
\hline E peak filling rate $\left(\mathrm{ml} \mathrm{s}^{-1}\right)$ & $415 \pm 55$ & $406 \pm 60$ \\
E deceleration $\left(\mathrm{ml} \mathrm{s}^{-2} \times 10^{-3}\right)$ & $3.7 \pm 1.9$ & $3.0 \pm 1.2$ \\
A-peak filling rate $\left(\mathrm{ml} \mathrm{s}^{-1}\right)$ & $311 \pm 57$ & $325 \pm 100$ \\
E/A-peak ratio & $1.37 \pm 0.25$ & $1.32 \pm 0.31$
\end{tabular}

Abbreviations: $\mathrm{A}=$ atrial diastolic wave; $\mathrm{CO}=$ cardiac output; $\mathrm{E}=$ early diastolic wave; $\mathrm{E} / \mathrm{Ea}=$ estimated left ventricular filling pressure; $\mathrm{EDV}=$ end-diastolic volume; $E S V=$ end-systolic volume; $E F=$ ejection fraction; $M R I=$ magnetic resonance imaging; $\mathrm{SV}=$ stroke volume. ${ }^{*} P<0.05,{ }^{\dagger} P<0.01$. Data are mean \pm s.d. 
after correction for heart rate. The other systolic LV parameters did not change after chemotherapy (Table 3).

Left ventricular E/A ratio decreased significantly after chemotherapy from $1.87 \pm 0.43$ to $1.64 \pm 0.45(P=0.009)$. In addition, the atrial peak filling rate increased significantly after chemotherapy. The LV E/A ratio and the atrial peak filling rate were not significantly influenced by the increased heart rate, thus correction for heart rate was not required. Other LV diastolic function parameters did not change after chemotherapy.

Right ventricular EDV and SV decreased significantly from $210 \pm 32$ to $196 \pm 32 \mathrm{ml}$ and from $105 \pm 14(P=0.011)$ to $93 \pm 16$ $(P=0.038)$, respectively. Both parameters were influenced by the increased heart rate. After the correction for heart rate, the difference between baseline and follow-up remained statistically significant. All other RV parameters, systolic or diastolic, remained unchanged after chemotherapy (Table 3 ).

\section{Fat distribution}

Myocardial TG content. Baseline and follow-up data from eight myocardial ${ }^{1} \mathrm{H}-\mathrm{MR}$ spectra were present. Myocardial TG content did not significantly change after chemotherapy. At baseline TG content was $0.69 \pm 0.41 \%$, after chemotherapy $0.74 \pm 0.35 \%$ $(P=0.742)$.

Pericardial fat. Pericardial fat volume did not change significantly after chemotherapy, $27.0 \pm 3.9 \mathrm{ml}$ at baseline and $28.1 \pm 5.5 \mathrm{ml}$ early after chemotherapy $(P=0.343)$.

Visceral and subcutaneous fat. One waist fat MRI scan was missing. Visceral fat volume increased significantly from $186 \pm 125$ to $227 \pm 162 \mathrm{ml}(P=0.039)$, whereas subcutaneous fat volume did not change. The visceral/subcutaneous fat ratio did significantly increase from $0.38 \pm 0.11$ to $0.42 \pm 0.12(P=0.025)$.

\section{DISCUSSION}

The main finding of this study is that LV diastolic function is decreased 3 months after start of cisplatin-based chemotherapy for TC. Decreased diastolic function was accompanied by an unfavourable change in metabolic profile as measured by increased serum LDL and total cholesterol and decreased insulin sensitivity. In addition, visceral fat volume and visceral/subcutaneous fat ratio increased. Several studies reported increased cardiovascular risk factors, increased incidence of cardiovascular disease and diminished cardiac function as long-term complications years after treatment with cisplatin-based chemotherapy (Meinardi et al, 2000; Huddart et al, 2003; Nuver et al, 2005a; Haugnes et al, 2010; Altena et al, 2011). Only few studies report on the subacute cardiovascular effects of cisplatin-based chemotherapy (Nuver et al, 2005b; Altena et al, 2009; Nuver et al, 2010). To the best of our knowledge, we are the first to investigate the acute effects of chemotherapy on cardiac function. Altena et al (2009) showed deterioration of diastolic heart function assessed with echocardiography $\sim 10$ months after chemotherapy. In contrast, we assessed cardiac function immediately after completion of chemotherapy.

In the present study, the LV E/A ratio decreased, reflecting deterioration in diastolic LV function. As the E/A ratio is load dependent and thus influenced by the filling status of the patient, an estimation of LV filling pressure was determined (E/Ea) (Paelinck et al, 2005), which did not change after chemotherapy. Therefore, the decreased E/A ratio after chemotherapy presumably reflects disturbed intrinsic relaxation of the $\mathrm{LV}$, rather than change in LV filling pressure. A previous study showed progressive deterioration of diastolic heart function, 10 months and 6.9 years after cisplatin-based chemotherapy (Haas de et al, 2013).
Therefore, acute changes in diastolic function observed in the present study might be of prognostic clinical significance. Longterm follow-up data of our patient group would be interesting to have some information of the predictive value of these early cardiac changes. Left ventricular EF (LVEF), an important parameter of systolic function, did not change. Change in the LV diastolic function with preserved LVEF after treatment with cisplatin-based chemotherapy is in line with previous studies (Nuver et al, 2005a; Altena et al, 2009; Altena et al, 2011). It is known that diastolic dysfunction precedes a decline in systolic function and can be regarded as an important prognostic marker of ongoing disease (Naressi et al, 2001; Nuver et al, 2010). For future studies, it would be interesting to combine echocardiography with cardiac MRI, as previous studies suggest that early impairment of systolic function may also be detected using strain echocardiography and that it could be predictive of subsequent reduction in LVEF (Monsuez, 2012). Furthermore, in further studies biomarkers such as $\mathrm{N}$-terminal pro-brain natriuretic peptide and troponin I could be determined, because determination of these biomarkers may be useful in the evaluation of early cardiac toxicity (Monsuez, 2012).

Cisplatin can directly injure cardiomyocytes through oxidative stress and mitochondrial damage (Nuver et al, 2004). In addition, cisplatin and bleomycin cause decreased endothelial cell survival and induce apoptosis of endothelial cells in vitro (Nuver et al, 2010). These endothelial changes may promote inflammation and atherosclerosis, which can contribute to chemotherapy-induced vascular toxicity. In addition, endothelial cells at the endocardium have an obligatory role in maintaining cardiac function (Brutsaert, 2003). Cisplatin-based chemotherapy may also indirectly lead to cardiovascular disease, via increased prevalence of cardiovascular risk factors (de Haas et al, 2010; Haugnes et al, 2010). Increased prevalence of cardiovascular risk factors, such as dyslipidemia, central obesity and insulin resistance, can lead to accelerated atherosclerosis (Nuver et al, 2004). In this study, the follow-up time is presumably too short for these indirect effects of chemotherapy to contribute to impaired cardiac function. We could not establish a direct relationship between cardiac function and metabolic profile. However, already 3 months after start of chemotherapy, we identify a shift to an unfavourable metabolic profile: visceral fat volume, visceral/subcutaneous fat ratio, lowdensity lipoprotein-cholesterol and total cholesterol were increased and insulin sensitivity decreased. Visceral fat is more deleterious than subcutaneous fat and is associated with the metabolic syndrome and cardiovascular disease (Despres and Lemieux, 2006; Mathieu et al, 2008; de Haas et al, 2010). The metabolic syndrome consists of a cluster of risk factors: dyslipidemia, hypertension, central obesity and insulin resistance. This syndrome is associated with a long-term increased risk for atherosclerotic disease (Alberti et al, 2006; de Haas et al, 2010), with cardiovascular disease as one of the major complications. Via insulin resistance and the concomitant increased release of adipokines such as resistin, the metabolic syndrome is associated with endothelial dysfunction (Verma et al, 2003). High C-reactive protein (CRP) levels are associated with the metabolic syndrome and endothelial dysfunction (Devaraj et al, 2011). In this study we did not measure CRP levels unfortunately, but in subsequent studies these levels should be measured. A recent study showed that the metabolic syndrome is more prevalent and develops at earlier age in TC survivors, treated with cisplatin-based chemotherapy (Haas de et al, 2013). Visceral adipose tissue contributes to insulin resistance (Mathieu et al, 2008), which is associated with decreased cardiac function (Battiprolu et al, 2010; Rijzewijk et al, 2009; Voulgari et al, 2010), even in the absence of diabetes mellitus (Bajraktari et al, 2006; Dinh et al, 2010). In the metabolic syndrome, insulin resistance and (visceral) adiposity is correlated with myocardial TG accumulation, which might negatively influence cardiac function (Kankaanpaa et al, 2006; 
Hammer et al, 2008). In this study, we did not find a difference between myocardial TG content before and after chemotherapy. The number of measurements of myocardial TG $(N=8)$ content is probably too small to draw firm conclusions regarding myocardial TG changes early after chemotherapy. Another explanation could be that the follow-up period is too short, so the oxidative capacity of the myocardium is still sufficient, preventing storage of TG in the myocardium.

Diastolic cardiac function progressively deteriorates in TC survivors treated with cisplatin-based chemotherapy (Altena et al, 2011). Subclinical changes in cardiac diastolic function may therefore precede late clinical dysfunction. If these early changes are predictive for later abnormalities in cardiac function, such changes may be used to monitor patients more specifically. Furthermore, patients treated with cisplatin-based chemotherapy are at increased risk of developing an unfavourable cardiovascular risk profile, which can contribute to development of long-term cardiac failure. Accordingly, early detection of risk factors for cardiovascular disease is important, as treatment of the unfavourable metabolic changes with lifestyle intervention or medication can contribute to an improved long-term prognosis in patients treated with cisplatin-based chemotherapy.

In conclusion, treatment with cisplatin-based chemotherapy for TC induces acute alterations in diastolic cardiac function, paralleled by unfavourable metabolic changes. Although the predictive significance of the diastolic cardiac changes for longterm cardiovascular morbidity is not clear at present, it seems plausible that they may eventually lead to overt cardiovascular disease. As the detrimental metabolic changes can contribute to the development of cardiovascular disease, these risk factors should be monitored and treated if necessary.

\section{ACKNOWLEDGEMENTS}

Funding by The Netherlands Heart Foundation (Project UL 20094548 ) is gratefully acknowledged (The Hague, The Netherlands).

\section{REFERENCES}

Alberti KG, Zimmet P, Shaw J (2006) Metabolic syndrome-a new worldwide definition. A Consensus Statement from the International Diabetes Federation. Diabet Med 23(5): 469-480.

Altena R, de Haas EC, Nuver J, Brouwer CA, van den Berg MP, Smit AJ, Postma A, Sleijfer DT, Gietema JA (2009) Evaluation of sub-acute changes in cardiac function after cisplatin-based combination chemotherapy for testicular cancer. Br J Cancer 100(12): 1861-1866.

Altena R, Hummel YM, Nuver J, Smit AJ, Lefrandt JD, de Boer RA, Voors AA, van den Berg MP, de Vries EG, Boezen HM, Gietema JA (2011) Longitudinal changes in cardiac function after cisplatin-based chemotherapy for testicular cancer. Ann Oncol 22(10): 2286-2293.

Bajraktari G, Koltai MS, Ademaj F, Rexhepaj N, Qirko S, Ndrepepa G, Elezi S (2006) Relationship between insulin resistance and left ventricular diastolic dysfunction in patients with impaired glucose tolerance and type 2 diabetes. Int J Cardiol 110(2): 206-211.

Battiprolu PK, Gillette TG, Wang ZV, Lavandero S, Hill JA (2010) Diabetic cardiomyopathy: mechanisms and therapeutic targets. Drug Discov Today Dis Mech 7(2): e135-e143.

Brutsaert DL (2003) Cardiac endothelial-myocardial signaling: its role in cardiac growth, contractile performance, and rhythmicity. Physiol Rev 83(1): 59-115.

de Haas EC, Oosting SF, Lefrandt JD, Wolffenbuttel BH, Sleijfer DT, Gietema JA (2010) The metabolic syndrome in cancer survivors. Lancet Oncol 11(2): 193-203.

Despres JP, Lemieux I (2006) Abdominal obesity and metabolic syndrome. Nature 444(7121): 881-887.

Devaraj S, Kumaresan PR, Jialal I (2011) C-reactive protein induces release of both endothelial microparticles and circulating endothelial cells in vitro and in vivo: further evidence of endothelial dysfunction. Clin Chem 57(12): 1757-1761.

Dinh W, Lankisch M, Nickl W, Scheyer D, Scheffold T, Kramer F, Krahn T, Klein RM, Barroso MC, Futh R (2010) Insulin resistance and glycemic abnormalities are associated with deterioration of left ventricular diastolic function: a cross-sectional study. Cardiovasc Diabetol 9: 63.

Einhorn EH (1997) Testicular cancer: an oncological success story. Clin Cancer Res 3(12 Pt 2): 2630-2632.

Haas de EC, Altena R, Boezen HM, Zwart N, Smit AJ, Bakker SJL, van Roon AM, Postma A, Wolffenbuttel BHR, Hoekstra HJ, van Leeuwen FE, Sleijfer DT, Gietema JA (2013) Early development of the metabolic syndrome after chemotherapy for testicular cancer. Ann Oncol 24(3): 749-755.

Hammer S, Snel M, Lamb HJ, Jazet IM, van der Meer RW, Pijl H, Meinders EA, Romijn JA, de Roos A, Smit JW (2008) Prolonged caloric restriction in obese patients with type 2 diabetes mellitus decreases myocardial triglyceride content and improves myocardial function. J Am Coll Cardiol 52(12): 1006-1012.

Haugnes HS, Wethal T, Aass N, Dahl O, Klepp O, Langberg CW, Wilsgaard T, Bremnes RM, Fossa SD (2010) Cardiovascular risk factors and morbidity in long-term survivors of testicular cancer: a 20-year follow-up study. J Clin Oncol 28(30): 4649-4657.

Huddart RA, Norman A, Shahidi M, Horwich A, Coward D, Nicholls J, Dearnaley DP (2003) Cardiovascular disease as a long-term complication of treatment for testicular cancer. J Clin Oncol 21(8): 1513-1523.

International Germ Cell Cancer Collaborative Group (1997) International Germ Cell Consensus Classification: a prognostic factor-based staging system for metastatic germ cell cancers. J Clin Oncol 15(2): 594-603.

Jonker JT, Lamb HJ, van der Meer RW, Rijzewijk LJ, Menting LJ, Diamant M, Bax JJ, de Roos A, Romijn JA, Smit JW (2010) Pioglitazone compared with metformin increases pericardial fat volume in patients with type 2 diabetes mellitus. J Clin Endocrinol Metab 95(1): 456-460.

Kankaanpaa M, Lehto HR, Parkka JP, Komu M, Viljanen A, Ferrannini E, Knuuti J, Nuutila P, Parkkola R, Iozzo P (2006) Myocardial triglyceride content and epicardial fat mass in human obesity: relationship to left ventricular function and serum free fatty acid levels. J Clin Endocrinol Metab 91(11): 4689-4695.

Katz A, Nambi SS, Mather K, Baron AD, Follmann DA, Sullivan G, Quon MJ (2000) Quantitative insulin sensitivity check index: a simple, accurate method for assessing insulin sensitivity in humans. J Clin Endocrinol Metab 85(7): 2402-2410.

Lamb HJ, Doornbos J, van der Velde EA, Kruit MC, Reiber JH, de Roos A (1996) Echo planar MRI of the heart on a standard system: validation of measurements of left ventricular function and mass. J Comput Assist Tomogr 20(6): 942-949.

Mathieu P, Pibarot P, Larose E, Poirier P, Marette A, Despres JP (2008) Visceral obesity and the heart. Int J Biochem Cell Biol 40(5): 821-836.

Meinardi MT, Gietema JA, van der Graaf WT, van Veldhuisen DJ, Runne MA, Sluiter WJ, de Vries EG, Willemse PB, Mulder NH, van den Berg MP, Koops HS, Sleijfer DT (2000) Cardiovascular morbidity in long-term survivors of metastatic testicular cancer. J Clin Oncol 18(8): 1725-1732.

Monsuez JJ (2012) Detection and prevention of cardiac complications of cancer chemotherapy. Arch Cardiovasc Dis 105(11): 593-604.

Montiel M, Urso L, de la Blanca EP, Marsigliante S, Jimenez E (2009) Cisplatin reduces endothelial cell migration via regulation of type 2-matrix metalloproteinase activity. Cell Physiol Biochem 23(4-6): 441-448.

Naressi A, Couturier C, Castang I, de Beer R, Graveron-Demilly D (2001) Java-based graphical user interface for MRUI, a software package for quantitation of in vivo/medical magnetic resonance spectroscopy signals. Comput Biol Med 31(4): 269-286.

Nuver J, de Haas EC, Van Zweeden M, Gietema JA, Meijer C (2010) Vascular damage in testicular cancer patients: a study on endothelial activation by bleomycin and cisplatin in vitro. Oncol Rep 23(1): 247-253.

Nuver J, Smit AJ, Sleijfer DT, van Gessel AI, van Roon AM, van der Meer J, van den Berg MP, Burgerhof JG, Hoekstra HJ, Sluiter WJ, Gietema JA (2004) Microalbuminuria, decreased fibrinolysis, and inflammation as early signs of atherosclerosis in long-term survivors of disseminated testicular cancer. Eur J Cancer 40(5): 701-706.

Nuver J, Smit AJ, Sleijfer DT, van Gessel AI, van Roon AM, van der Meer J, van den Berg MP, Hoekstra HJ, Sluiter WJ, Gietema JA (2005a) Left ventricular and cardiac autonomic function in survivors of testicular cancer. Eur J Clin Invest 35(2): 99-103. 
Nuver J, Smit AJ, van der Meer J, van den Berg MP, van der Graaf WT, Meinardi MT, Sleijfer DT, Hoekstra HJ, van Gessel AI, van Roon AM, Gietema JA (2005b) Acute chemotherapy-induced cardiovascular changes in patients with testicular cancer. J Clin Oncol 23(36): 9130-9137.

Paelinck BP, de Roos A, Bax JJ, Bosmans JM, van der Geest RJ, Dhondt D, Parizel PM, Vrints CJ, Lamb HJ (2005) Feasibility of tissue magnetic resonance imaging: a pilot study in comparison with tissue Doppler imaging and invasive measurement. J Am Coll Cardiol 45(7): 1109-1116.

Pattynama PM, Lamb HJ, van der Velde EA, van der Wall EE, de Roos A (1993) Left ventricular measurements with cine and spin-echo MR imaging: a study of reproducibility with variance component analysis. Radiology 187(1): 261-268.

Raghavan D, Cox K, Childs A, Grygiel J, Sullivan D (1992) Hypercholesterolemia after chemotherapy for testis cancer. J Clin Oncol 10(9): 1386-1389.

Rijzewijk LJ, van der Meer RW, Lamb HJ, de Jong HW, Lubberink M, Romijn JA, Bax JJ, de Roos A, Twisk JW, Heine RJ, Lammertsma AA, Smit JW, Diamant M (2009) Altered myocardial substrate metabolism and decreased diastolic function in nonischemic human diabetic cardiomyopathy: studies with cardiac positron emission tomography and magnetic resonance imaging. J Am Coll Cardiol 54(16): 1524-1532.

Rijzewijk LJ, van der Meer RW, Smit JW, Diamant M, Bax JJ, Hammer S, Romijn JA, de Roos A, Lamb HJ (2008) Myocardial steatosis is an independent predictor of diastolic dysfunction in type 2 diabetes mellitus. J Am Coll Cardiol 52(22): 1793-1799.

Stefenelli T, Kuzmits R, Ulrich W, Glogar D (1988) Acute vascular toxicity after combination chemotherapy with cisplatin, vinblastine, and bleomycin for testicular cancer. Eur Heart J 9(5): 552-556.

van der Meer RW, Doornbos J, Kozerke S, Schar M, Bax JJ, Hammer S, Smit JW, Romijn JA, Diamant M, Rijzewijk LJ, de Roos A, Lamb HJ (2007) Metabolic imaging of myocardial triglyceride content: reproducibility of $1 \mathrm{H}$ MR spectroscopy with respiratory navigator gating in volunteers. Radiology 245(1): 251-257.

Verma S, Li SH, Wang CH, Fedak PW, Li RK, Weisel RD, Mickle DA (2003) Resistin promotes endothelial cell activation: further evidence of adipokine-endothelial interaction. Circulation 108(6): 736-740.

Voulgari C, Papadogiannis D, Tentolouris N (2010) Diabetic cardiomyopathy: from the pathophysiology of the cardiac myocytes to current diagnosis and management strategies. Vasc Health Risk Manag 6: 883-903.

This work is published under the standard license to publish agreement. After 12 months the work will become freely available and the license terms will switch to a Creative Commons AttributionNonCommercial-Share Alike 3.0 Unported License. 